DOI: 10.12731/2227-930X-2019-3-57-63

УДК 697.34

\title{
К ВОПРОСУ УПРАВЛЕНИЯ ГИДРАВЛИЧЕСКИМИ РЕЖИМАМИ ТЕПЛОВОЙ СЕТИ
}

\author{
Алексеев А.А., Кнюк А.В.
}

Используется программа математического моделирования Computational fluid dynamics. Исследования позволяют учесть все факторы, влияющче на изменение гидростатического давления, изучить процесс взаимодействия цииркуляционного насоса, подпиточного узла и работы турбины на потребителе.

Ключевые слова: тепловая сеть; гидростатические и гидродинамические режимы; характеристика сети; математическое моделирование; энергосбережение; энергетическая эффективность; теплоснабжение.

\section{TO THE QUESTION OF CONTROL OF HYDRAULIC MODES OF THE HEAT NETWORK}

\section{Alekseev A.A., Knyuk A.V.}

The mathematical modeling program Computational fluid dynamics is used. Research allows you to take into account all the factors affecting changes in hydrostatic pressure, to study the interaction process of the circulation pump, make-up unit and the operation of the turbine on the consumer.

Keywords: heat network; hydrostatic and hydrodynamic modes; network characteristic; mathematical modeling; energy saving; energy efficiency heat supply.

\section{Введение}

Структура теплоснабжения не допускает нерациональных решений развития, которые приводят к неэффективному использованию энергоресурсов. Нормы и требования федеральных законов 
ужесточаются и обязывают постоянно задаваться вопросом дальнейшего энергетического развития. В связи с регулированием на законодательном уровне и исчерпаемыми энергоресурсами, вопросы энергосбережения не утратят своей актуальности.

Гидравлические режимы работы тепловых сетей в условиях неравномерной автоматизации [1] оказывают существенное влияние на качество и энергоэффективность теплоснабжения. От точности расчетов гидравлических режимов зависит величина эксплуатационных издержек и качество теплоснабжения. При расчёте режимов использован метод анализа потокораспределения в регулируемых трубопроводных системах [2], который является модификацией наиболее известного в настоящее время метода Тодини применительно к расчету потокораспределения. Для определения коэффициента гидравлического трения в трубах использована методика [3].

\section{Материалы и методы исследования}

Для исследования влияния подпиточного узла на систему, принципиальная схема которой представлена на рис.1 с температурным графиком $150 / 70^{\circ} \mathrm{C}$, располагаемым перепадом давления в сети, $\mathrm{dPH.}=60$ м. вод. ст.

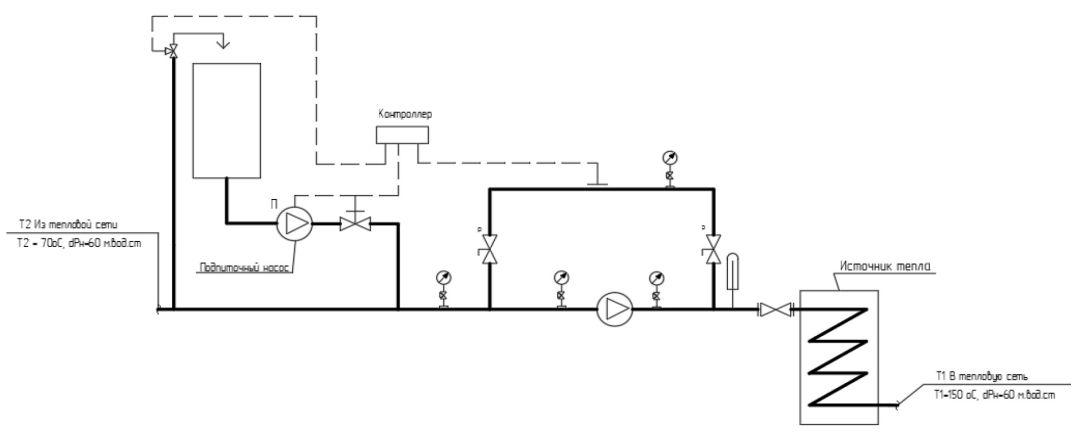

Рис. 1. Принципиальная схема системы теплоснабжения

Согласно принципиальной схеме, строим математическую модель тепловой сети в программе математического расчета, принимая все исходные параметры тепловой сети. 
Задаем параметры циркуляционного насоса, таким образом, чтобы в магистральном трубопроводе скорость воды равнялась 0,8 м/с. Также производим гидравлический расчет согласно методике [2]. Проверяем модель на наличие ошибок (соединения, правильность установки параметров, сетку). Результат расчета см. рисунок 2. Циркуляционный насос задается условно, поэтому в программе он не отображается.

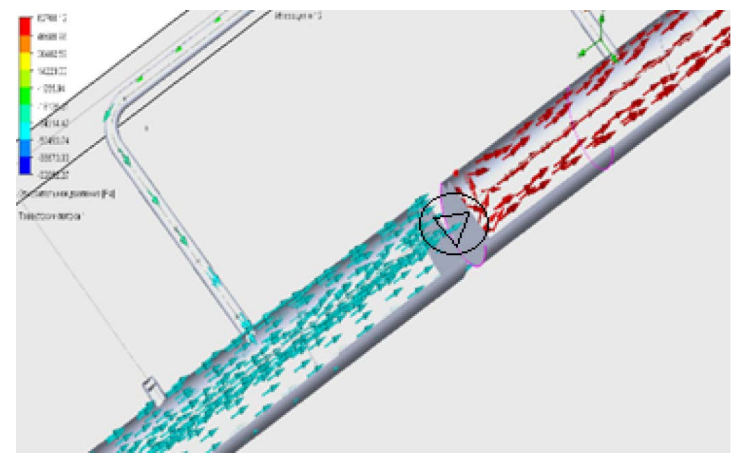

Рис. 2. Исходное состояние сети

Поток на входе в циркуляционный насос ламинарный, при выходе - турбулентный.

Также наблюдается изменение статического давления в сети при работе подпиточного насоса. На выходе подпиточного узла наблюдается повышение давления в сети почти в 2 раза, поток упирается стенку трубопровода тем самым заполняя систему (рис. 3).

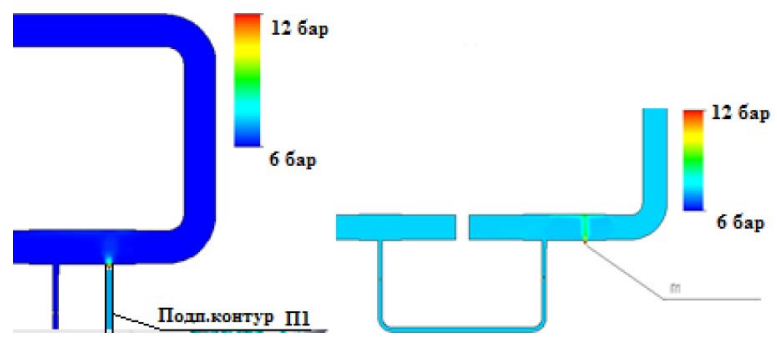

Рис. 3. Принцип работы подпиточного контура 


\section{Результаты исследования}

Таким образом, результаты построения математической модели подпиточного узла позволяют оценить влияние жидкости на стенки трубопровода, потокораспределение при выходе и влияние на всю систему в целом. Данная модель позволяет разработать принципиальную схему для экономии электроэнергии, которую мы описываем далее.

\section{Обсуждение}

На сегодняшний день существующие индивидуальные пункты не отвечают критериям энергетической эффективности и энергосбережению, не малая доля ещё остаётся зависимых и открытых систем теплоснабжения. Предлагаем рассмотреть индивидуальный пункт потребителей систем теплоснабжения и задаться вопросом: «На максимум ли мы полезно используем получаемый теплоноситель от источников системы теплоснабжения»? Самое основное мы получаем температуру через поверхность нагрева от получаемого теплоносителя, но не предусматриваем как полезно использовать получаемую энергию от источника, который её затрачивает для транспортировки к потребителям. Предлагаем рассмотреть одну из возможных модернизаций тепловых пунктов сети теплоснабжения, с помощью преобразования энергии потока теплоносителя (см. рис. 4).

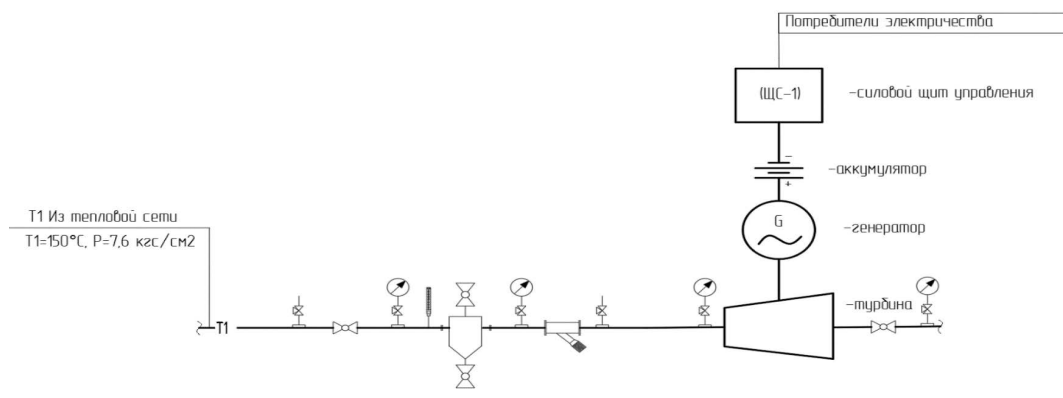

Рис. 4. Принципиальная схема ИТП с использованием турбины

На рисунке 4 показана схема преобразования потока энергии получаемого теплоносителя и основные варианты дальнейшего ис- 
пользования выработанной электрической энергии. Установка ротора турбины рекомендуется на подающем трубопроводе после узла очистки получаемого теплоносителя. Данное размещение обусловлено максимальным давлением в сети, а после узла очистки исходя из качества теплоносителя. Данная модернизация разгрузит источники сети теплоснабжения в зимний период во время холодной пятидневки при использовании подачи выработанной электроэнергии на доп. нагрев нагреваемого контура в теплообменниках и другие потребители теплоты. В летний и переходные периоды основное снабжение электроэнергией в приборы освещения и снабжение насосных агрегатов с точки зрения экономической целесообразности.

\section{Заключение}

Исходя из совместной работы подпиточного узла тепловой сети и работы турбины на источнике, можно преобразовать механическую энергию в электрическую, а именно увеличение гидростатического давления, что позволит обеспечить потребителей требуемыми параметрами давления, и, как следствие, потребитель сможет максимально получать электрическую энергию с помощью турбины на ИТП, что особенно будет очень актуально для потребителей, подключённых в непосредственной близости от источника теплоснабжения.

Информация о конфликте интересов. Авторы заявляют об отсутствии конфликта интересов.

Информация о спонсорстве. Исследование не имело спонсорской поддержки.

\section{Сиисок литературы}

1. Липовка Ю.Л., Калабин Д.А. Гидравлическая устойчивость в условиях неравномерной автоматизации систем теплоснабжения // Энергосбережение и водоподготовка. 2018. № 3 (113). С. 19-24.

2. Lipovka A.J., Lipovka Y.L. Application of «Gradient» Algorithm to Modeling Thermal Pipeline Networks with Pumping Stations // Journal 
of Siberian Federal University. 1 Engineering \& Technologies (2013 6), 28-35.

3. Lipovka A.J., Lipovka Y.L. Determining Hydraulic Friction Factor for Pipeline Systems // Journal of Siberian Federal University. 1 Engineering \& Technologies (2014 1), 62-82.

\section{References}

1. Lipovka Yu.L., Kalabin D.A. Gidravlicheskaya ustoychivost' v usloviyakh neravnomernoy avtomatizatsii sistem teplosnabzheniya [Hydraulic stability in conditions of uneven automation of heat supply systems]. Energosberezhenie $i$ vodopodgotovka [Energy conservation and water treatment]. 2018. No. 3 (113), pp. 19-24.

2. Lipovka A.J., Lipovka Y.L. Application of «Gradient» Algorithm to Modeling Thermal Pipeline Networks with Pumping Stations. Journal of Siberian Federal University. 1 Engineering \& Technologies (2013 6), 28-35.

3. Lipovka A.J., Lipovka Y.L. Determining Hydraulic Friction Factor for Pipeline Systems. Journal of Siberian Federal University. 1 Engineering \& Technologies (2014 1), 62-82.

\section{ДАННЫЕ ОБ АВТОРАХ}

Алексеев Алексей Андреевич, аспирант

Сибирский федеральнылй университет

пр. Свободньй, 79, Красноярск, 660041, Российская Федеращия Alexeev.alexey.ru@mail.ru

Кнюк Александр Витальевич, аспирант

Сибирский федеральный университет

пр. Свободньй, 79, Красноярск, 660041, Российская Федерациия

\section{DATA ABOUT THE AUTHORS}

Alekseev Alexey Andreevich, graduate student, Institute of Civil Engineering 
Siberian Federal University

79, Svobodny, Krasnoyarsk, 660041 Russian Federation

Alexeev.alexey.ru@mail.ru

ORCID: 0000-0001-5078-7364

Knyuk Alexander Vitalievich, graduate student, Institute of Civil Engineering

Siberian Federal University

79, Svobodny, Krasnoyarsk, 660041 Russian Federation 